\title{
THE DEVELOPMENT OF MEDICAL SOCIOLOGY IN THE POST-SOVIET SOCIETY: THE CASE OF LITHUANIA
}

\author{
Raimundas Kaminskas, Eimantas Peičius \\ Department of Philosophy and Social Sciences, Kaunas University of Medicine, Kaunas, Lithuania
}

\begin{abstract}
SUMMARY
This article explores the historical development of medical sociology and analyses the social problems that have had impacted the changes of health care institutionalization particularly in Lithuania during the Soviet and post-soviet period. Approaching the interaction between sociology and public health sciences, it is intended to apply the concept of medical sociology and its determinants in the context of health care and education systems. By analyzing the case past of medical sociology in Lithuania, we claim that its prospects should be associated with the study of new challenges in the biomedical sciences. In order to improve the importance of medical sociology in developing democracies we should focus on the questions, for instance, to what extent modern biotechnologies should be applied, how to improve the situation with patients' rights, and how to combine the knowledge of social sciences and biomedicine in order to improve the quality of healthcare services and to ensure better functioning of the healthcare system in particular district.
\end{abstract}

Key words: medical sociology, sociology in medicine, health sociology, public health, Lithuania

Address for correspondence: E. Peičius, Department of Philosophy and Social Sciences, Kaunas University of Medicine, Mickeviciaus 9 , Kaunas, LT-44307, Lithuania. E-mail: eimantas.peicius@med.kmu.lt; eimpei@takas.It

\section{INTRODUCTION}

Medicine and health started be the focus point of sociology just after World War II, but an intensive development of medical sociology started only around 1960-70, during significant economic, social, and political changes in the societies of the developed countries. Medical sociology in Lithuania (including other Baltic countries) is becoming public health specialists' new special "eyeglasses" that open much wider horizons of healthcare research, and thus significantly greater possibilities for a more profound analysis of healthcare problems such as physician-patient relationships etc.

It is noteworthy that the development of medical sociology is closely related to the development of the science of medicine and sociology in the 2 nd half of the 20th century. However, when speaking of the transition from sociology in medicine to medical sociology, and later on - to health sociology one should identify the main categories of medical practice, empirical studies, and sociological theory (1). Regarding this distinction sociology in medicine can be characterized as applied research primarily motivated by medical (not sociological) problem, as sociology in medicine primarily motivated by the solution of sociological (rather than medical) problems (2).

The main period of the development of medical sociology (during the predominance of sociology in medicine) was actually characterized by the predominance of the paradigmatic model of biological sciences (the biomedical model), whereas later on there was a shift towards the fields of psychology and social and humanitarian sciences - i.e. towards the biosocial model. Respective changes occurred in the levels emphasized in the sociological analysis (a shift from an individual towards complex social structures), as well as in the methods applied - studies of the organizational environment began (a transition from a separate hospital towards social control and socialization institutions), the scope of the studied social roles broadened, etc. $(3,4)$.

There was a shift from the analysis of social-psychological factors towards the institutional level of analysis, from the studies of micro-social relationships towards the analysis of macro-social systems, from the clarification of individuals' relationships and/or peculiarities of communication towards the analysis of power structures, from the analysis of individual roles limited by concrete conditions of the environment towards a complex organizational analysis, from behavior analysis using terms of elementary behaviorism towards the contextual analysis of policy in macro-social contexts, etc. This shift conditioned the development of a multitude of new branches of medical sociology and its application spheres, e.g. sociology of body, sociology of risk, etc. (5). In addition to that, new topics of studies in the field of medical sociology started forming. For instance, when analyzing issues of medical ethics (abortions, euthanasia, stem cell studies, etc.), sociologists pay increasingly more attention to the social-ethical content of new medical technologies, and present various evalu- 
ations of these phenomena (6). In this respect, empirical data are not interpreted in relation to social processes and the prospects of their models $(6,7)$.

Thus, it can be stated that today medical sociology, tackling such relevant topics as social aspects of physical and mental diseases, physician-patient relationships, organization and structure of healthcare institutions, socio-economic basics of the healthcare system, etc., is a fully institutionalized and independent branch of sociological studies.

So far we discussed examples of studies performed by Western researchers. In the post-Soviet dimension, these processes have been analyzed more in the context of politics and economics rather than social relationships (8). Meanwhile, it is noteworthy that in Lithuania, the very term medical sociology is not widely known. This article discusses the reasons for such limited spread of this branch of sociology in Lithuania (differently from other Western countries).

The aim of this article is to survey the development of medical sociology in post-Soviet Lithuania (including the Soviet period), as well as the future prospects of potential sociological studies. The method applied in this article is comparative-historical analysis.

\section{THE DEVELOPMENT OF MEDICAL SOCIOLOGY IN SOVIET LITHUANIA}

The first cases when medical professionals noticed social problems related to medical activity in Lithuania date back to the very beginning of the 19th century, when thanks to Prof. J. P. Frank's efforts the Departments of Hygiene and Forensic Medicine were established at Vilnius University, and the course on Social Hygiene and Forensic Medicine was introduced. However, further development of this initiative was aggravated by the socio-political situation in Lithuania. One can state that only the period of 1967-1972 may be considered to be the period of the differentiation and institutionalization of sociology in Soviet Lithuania.

Without going too deep into the political and ideological conditions of the Soviet totalitarianism, it suffices to say that during the Soviet period, when adapting to the requirements of the conjuncture, one could make a career by either partially or fully relying on influential relatives. A certain development of sociology in the Soviet Union allowed not only for the "testing" of the limitations set by the regime, but was also associated with the social conditions of the life of the society, and these conditions significantly differed from those in which medical sociology in the Western countries emerged.

It is obvious that the biomedical model of a disease $\mathrm{e}^{1}$ in the Soviet Union had more favorable conditions for rising to an absolute than in the capitalist democratic societies of the West. Medicine became the discipline for the objective diagnosis of diseases, whereas the patient and the physician as distinctive and subjective individuals were totally eliminated from the model $(8,9)$. Such biomedical approach was directly manifested with respect to citizens who transgressed the Soviet order - such people were sent to mental hospitals on the basis of "experts' conclusions" (10). Although the establishment of the biomedical model was a common tendency of the development of the European civilization, one can still state that in the Soviet Union this model was developed to the extreme. If in other European countries other non-allopathic approaches to treatment (herbal medicine, homeopathy, etc.) could exist alongside the orthodox biomedical model, in the Soviet Union all other approaches to treatment (such as alternative, herbal, or natural medicine) were eliminated (10). It is important to emphasize that the so-called non-orthodox (with respect to the biomedical model) treatment techniques require greater involvement of the patient as an active social agent into interaction with the physician, rather than attributing to $\mathrm{him} / \mathrm{her}$ the role of an individual that passively submits to the role of a patient, which means that the elimination of alternative treatment methods further decreased the possibility for the activeness of a diseased person (11).

Paradoxically, the biomedical model in the Soviet Union was especially associated with ideology, since marxism was based on the determinism of social conditions, i.e. it allowed for a strict separation of social, political, and cultural conditions from the biological ones, and thus the causes of a disease were sought only in the body and various microorganisms (this approach was called scientific materialism). The development of medical sociology in Soviet Lithuania may be relatively divided into the following stages:

1964-1972. The first scientific institutions of sociology after 1960 in the USSR were established at the departments of scientific communism, and theories of sociology were analyzed as criticism of bourgeois social theories. For instance, at Kaunas Medical Institute (KMI) nowadays - Kaunas University of Medicine (KMU) sociological studies were performed and their results were published after 1964. KMI was one of the centers of the development of medical sociology in Lithuania $(10,11)$. For a number of years, researchers at this higher educational institution investigated students' approaches to healthy lifestyle, and the main objectives of the studies were to determine how future health professionals - physicians, odontologists, and pharmacists - develop ideal features of the personality of a medical specialist. The unit of sociological studies was established at this institution.

1973-1988. In May 1973, a scientific laboratory for medical psychology and sociological research was established at KMI Institute of Scientific Research on Cardiovascular Physiology and Pathology (at present called KMU Institute of Cardiology). The establishment of such a specialized laboratory was conditioned by the need for psychological-sociological studies in the WHO-supervised Kaunas-Rotterdam Intervention Study (KRIS) that was initiated in 1972. This program became the beginning of new scientific studies in the prevention branch of the fields of medical psychology and health sociology (12).

In 1975, a separate department of sociologists of the Baltic countries (Lithuania, Latvia, and Estonia) was established within the USSR Association of Sociologists. This department had different units, including the Healthcare Sociology unit. The state list of professions in Lithuania did not contain the specialty of a sociologist, there was no education and training of specialists in this field, knowledge about medical sociology was accessible

${ }^{1}$ The biomedical approach to a disease is based on two principal premises: 1 . causes of the disease should be sought in human organism, since they are of biological origin; 2 . a disease is caused by a specific natural cause (e.g. a virus or a bacterium). 
only via a scarce number of specialized foreign scientific sources, and the doctoral dissertation in sociology could be defended only in several republics of the USSR, but not in Lithuania $(11,12)$.

During the Soviet period, sociology in medicine was predominantly oriented towards quantitative studies. This can be explained by several points. During the Soviet period, the so-called sociology in medicine clearly predominated in Lithuania. This means the predominant orientation towards quantitative studies, which, despite the above-discussed rapid theoretical and methodological changes in this field, in Lithuania (as in the whole USSR) underwent virtually no changes. Such stability (conservativeness) in medical (as well as in general) sociology during that period was conditioned by several reasons.

First, the society, science, and healthcare system in Lithuania (as well as, probably, in other republics of the USSR) during this period were especially laden with ideology; the same applies to nearly all fields of public and private life. This means that no other ideology or social theory was possible apart from the dogmatic marxism with its concept of an ideal (soviet) society that has no problems, including social problems of health. Objective qualitative analysis of social problems or institutions of healthcare was unfavorable towards the contemporary political conjuncture, and thus was practically impossible to perform (13).

Second, as we have mentioned, during the Soviet period there was virtually no suitable environment for the development of academic sociology. Professionals who performed sociological studies in the field of medicine most frequently associated sociology only with mathematical-statistical analysis and social epidemiology. It is noteworthy that inquiries related to epidemiology that were performed at that time remained on the level of methodized empirical data; at best, correlations of variables were calculated, but no sociological analysis of the perspective was made. On the one hand, such a situation in the Soviet medical sociology was conditioned by the biomedical model of health that was predominant at that time and "focused the attention of the health policy on the development of medical technologies" (12). On the other hand, the situation was undoubtedly influenced by the shortage of professional sociologists in Lithuania and the lack of a firm tradition of research in the field of social sciences. However, although "medical/health sociology was known via only several specialized books from abroad", in Lithuania dissertations on topics that at least relatively can be attributed to the field of medical sociology were defended throughout the whole Soviet period (9).

Third, the Soviet society was living in the conditions of continuous deficit, and thus healthcare could not acquire any features of the consumerist society (14). A patient could hardly be understood as a consumer with certain needs and rights without the presence of the very concept of a consumer ${ }^{2}$. Another limitation was that, according to the biomedical healthcare model, the patient was totally dependent on the physician. At the same time it can be stated that the crisis of healthcare in Soviet Lithuania could not be perceived because it did not exist ${ }^{3}$, but rather because, according to the biomedical healthcare model, the only things that could be overtly mentioned were quantitatively underdeveloped medical technologies, insufficient numbers of patients, physicians, hospital beds, etc.

\section{ELEMENTS OF THE INSTITUTIONALIZATION AND INCREASING PROFESSIONALISM OF MEDICAL SOCIOLOGY IN POST-SOVIET LITHUANIA}

Thus, during the Soviet period the predominant trend in Lithuania was the one that could be called sociology in medicine. However, in 1989 (at the beginning of the restoration of the Independence), the formation of a new national health policy of Lithuania was initiated, the reform of the system of science and studies began, and the formation of the civic and democratic society based on the principle of the free market started (15). All this inevitably influenced the development of medical sociology. After 1990, possibilities for the cooperation of the global (including scientific) society conditioned a more rapid emergence of the features of medical and health sociology in Lithuania during the last years of the 20th century started to open; these features were related to cultural anthropology, social theory, bioethics, and medical philosophy. For instance, in 1990 at Kaunas Medical Academy (KMA) (nowadays called Kaunas University of Medicine-KMU), the Department of philosophy and Social Sciences introduced a course on sociological studies for future health professionals (11). Later on, specialized disciplines - Sociology for medical specialists and Health sociology - were introduced for the first time in the history of sociology in Lithuania.

In 1994, scientists of the established Faculty of Public Health at KMA (together with KMU institute of Biomedical Studies) included various topics of medical sociology as a separate branch of science into the new interdisciplinary field of studies and research of health problems. The Institute of Public Health was established at the Faculty of Medicine at Vilnius University, and the subject of medical sociology was introduced at this Institute. At the Faculty of Health at Klaipeda University, the Department of Public Health was established; the subject of health sociology was introduced at this Department. In 1998, the Scientific Center for the Development of Public Health was established at Siauliai University. The first course books that included the concepts of medical sociology were published $(11,12)$.

Despite all this, it is obvious that empirical sociology in medicine is still predominant in Lithuania. It is worth remembering that sociology in medicine employs relatively limited quantitative models and techniques, and thus predetermines mechanical insight conclusions lacking the profound analysis of the effect of social factors on the dynamics of the development, the present state, the policy, and other aspects of public health $(16,17)$. This aggravates the elucidation of certain social problems of health, the search for the solution of such problems, and the possibilities for the realization of these solutions in the society (17). For this reason, the significantly increasing frequency of attempts to employ the advantages of medical sociology, as well as attempts to search for the explanations for medical phenomena not only in the demographic, but also in the socio-cultural contexts indicate

\footnotetext{
${ }^{2}$ It would probably be difficult to speak about a consumerist society that has no market, since only in the market conditions are individuals involved into continuous consumption that is stipulated by the producers' desire for profit.

${ }^{3}$ On the other hand, statements about the crisis of orthodox medicine in the presence of a totalitarian regime would have been pointless, since there were no data that would provide an empirical basis for such statements.
} 
that medical sociology has possibilities for successful development; more than that, they reflect the striving for a more effective application of the achievements of the science of public health for the wellbeing of people in the whole country as well as in the district of Eastern and Central Europe $(18,19)$.

\section{THE FUTURE PERSPECTIVES OF MEDICAL SOCI- OLOGY IN EASTERN EUROPE}

While analyzing the development of medical sociology during the last decades in Lithuania, the perspectives are based on the three basic determinants: its association with scientific research, specific socio-politics and socio-cultural environment of Lithuania. Following the advanced achievements of Western European scholars in medical sociology, its development should include the heritage of conservative tradition of quantitative research as well as new interdisciplinary qualitative approaches (20). Nevertheless the latest one is still regarded in Lithuania (presumably in other new EU members too) as hardly scientific, therefore so called biopsychosocial health model (WHO) is rather declared as necessity but not as reality.

Furthermore, the scientific integration process in the context of medical sociology implies a number of questions. How does medical sociology as education subject or as institutionalization tool contribute and enrich the biomedical research in general and public health research in particular? Is any role of medical sociology explaining some gaps of public health problems, regarding cultural, institutional and political changes? Some scientists have proved that the differentiation of medical sociology is more related to real power relationship among social players and institutionalization abilities but not to administrative changes only (21). Such kinds of questions are important because medical sociology as scientific subject is currently defined as multi-paradigmatic (pluralistic) academic course not merely inter-disciplinary (22). This allows researchers to formulate alternative theoretical approaches and strategies of empirical research, which is oriented to the wide interpretations of medical sociology, especially regarding to new membership in EU.

Today, graduates of a Lithuanian higher medical educational institution (alike graduates of respective institutions in Eastern Europe) possess ample knowledge about human organs, cells and their biochemical structures etc., but the list of the proposed/passed curricula raises doubts on whether such graduates possess adequate knowledge about the interactions and relationships between an individual as a social being, the family institution as the primary social group that determines his/her behavior, and the society as a system and/or the structure that conditions basic characteristics of social institutions (and the individual him/herself), and whether he/she is able to analyze them proficiently (23). This doubt leads to the statement that higher medical educational institutions in Lithuania should pay more attention to the position of various sociological subjects (both general and subjects of medical sociology) in curricula and research programs.

In addition to that, today in Lithuania it is important to (re)form medical thinking towards socialization not only in the society, but also in medicine itself, not only to develop research in medical sociology, but also to develop theory and create respective Lithua- nian terminology through the adoption of the global experience in this field (24).

The time has come to think about the establishment of a joint specialized scientific periodical of the association (society) of medical specialists and health sociologists, which would provide a significant stimulus for the institutionalization of medical sociology in Lithuania, and would help to overcome the lag in this field (compared to the Western countries) conditioned by the past events.

Thus, it is logical to think that it is expedient to work systematically in order to develop studies and research in the field of medical sociology in Lithuania both at present and in the future. The rapid development of science and the amalgamation of different fields of science as well as the separation and crystallization of new fields of science conditioned today medical sociology embraces not only the concepts of sociology in medicine, medical sociology, or health sociology, but also such narrow specific problematic issues as Sociology of Medical Science and Technology, Sociology of Medical Institutes, Sociology of Health Service, Sociology of Tele-medicine/Tele-health Care, Sociology of Emotions, etc.

\section{CONCLUSIONS}

Medical sociology is a new interdisciplinary (as well as applied) field of science that forms the research area within modern health policy and public health. The importance of medical sociology manifests itself when analyzing changes in the healthcare system in the post-Soviet societies, including the case of Lithuania. Medical sociology allows for a new approach to typical medical phenomena and for the supplementation of the epidemiological perspective of public health with socialqualitative analysis. In other words, medical sociology forms a pluralistic approach, thus moving biomedical sciences closer to wider social strata, elucidating the previously isolated activity of medical institutions, and providing more possibilities for civic initiatives in healthcare.

In general, one can state that despite relatively intensive participation of Lithuanian health professionals in international health research projects, the inclusion of sociology into the studies was impeded not only by ideological limitations, but also by differences in the social and economic conditions between the Western and the Soviet societies; these conditions could limit the possibility to notice social aspects of health. One can assume that medical specialists even could not employ sociology, since they did not fully understand the social processes that conditioned the shift in the concept of health and health policy in the West. Different social, economic, and political conditions simply did not allow for noticing that.

Although the development of medical sociology as an independent branch of science in Lithuania was impeded during separate periods of time, recent scientific research in this field demonstrates evident approach to the modern dominating research topics and techniques in this field of science. Such tendencies indicate a rapid approach of the Lithuanian scientific community to the general scientific standards that predominate in the whole world undergoing globalization. The prospects of medical sociology should be associated with the analysis of new challenges, for 
instance, to what extent modern biotechnologies should be applied, how to improve the situation with patients' rights, and how to combine the knowledge of social sciences and biomedicine in order to improve the quality of healthcare services and to ensure better functioning of the healthcare system in Lithuania as well as in the whole of Eastern and Central Europe.

\section{REFERENCES}

1. Annandale E. The Sociology of health and medicine: a critical introduction. Cambridge: Polity; 2001.

2. Cockerham WC, Ritchey FJ. Dictionary of medical sociology. Westport (USA): Greenwood Press; 1997.

3. Weitz R. The Sociology of Health, illness and health care: a critical approach. 3rd ed. Belmont (CA): Wadsworth/Thomson Learning; 2004.

4. Blaxter M. Medical sociology at the start of the new millennium. Soc Sci Med. 2000 Oct;51(8):1139-42.

5. Twaddle AC, Hessler RM. A sociology of health. 2nd ed. New York: Macmillan Publishing Company; 1987.

6. Lopez J. How sociology can save bioethics . . . maybe. Sociol Health Illn. 2004 Nov;26(7):875-96.

7. Zussman R. Sociological perspectives on medical ethics and decisionmaking. Annu Rev Sociol. 1997;23:171-89.

8. McKee M, Fister K. Post-communist transition and health in Europe. BMJ. 2004 Dec 11;329(7479):1355-6.

9. Leonavicius V. The reception of sociology in Lithuania: the case of sociology of health. Filosofija. Sociologija. 2003;(2):35-40. (In Lithuanian.)

10. Leonavicius $\mathrm{V}$. The discourse of sociology and studies in sociology in Lithuania universities. Filosofija. Sociologija. 2002;(1):24-9. (In Lithuanian.)

11. Zemaitaitis A, Kaminskas R, Novelskaite A. The development of medical sociology and its perspectives. Filosofija. Sociologija. 2004;(1):39-48. (In Lithuanian.)
12. Grabauskas V. Health policy development in Lithuania. WHO Reg Publ Eur Ser. 2000;86:82-93.

13. Ostrowska A. The development of medical sociology in Eastern Europe, 1965-1990. Eur J Public Health. 1996;6(2):100-4.

14. Lazutka R. Population's income inequality. Filosofija. Sociologija. 2003;(2):22-9. (In Lithuanian.)

15. Health care systems in transition: Lithuania. Copenhagen: WHO; 1996.

16. Blane D. The use of quantitative medical sociology. Sociol Health Illn. 2003 Apr;25(3):115-30.

17. Appelstrand M. Participation and societal values: the challenge for lawmakers and policy practitioners. Forest Policy Econ. 2002 Dec;4(4):28190.

18. Topinková E. Health care services for elderly in Czech Republic: new trends and future development. Cent Eur J Public Health. 1994 Dec;2(2):118-21.

19. Tahin E, Morava E. History of the Public Health Institute of Semmelweis Medical University, Budapest. Cent Eur J Public Health. 2000 May;8(2):104-8.

20. Gevers J, Gelissen J, Arts W, Muffels R. Public health care in the balance: exploring popular support for health care systems in the European Union. Int J Soc Welf. 2000 Oct;9(4):301-21.

21. Bloom SW. Episodes in the institutionalization of medical sociology: a personal view. J Health Soc Behav. 1990 Mar;31(1):1-10.

22. Evans M. Reflections on the humanities in medical education. Med Educ. 2002 Jun;36(6):508-13.

23. Contandriopoulos D. A sociological perspective on public participation in health care. Soc Sci Med. 2004 Jan;58(2):321-30.

24. Bencko V, Hnilicová H, Klein O. Quality of life, sustainable future and medical education. Cent Eur J Public Health. 2005 Sep;13(3):112-6.

Received July 18, 2006 Received in revised form and accepted December 12, 2006 